\title{
Verruciform xanthoma located in anterior gingiva
}

\author{
Márcia Hatakeyama ${ }^{1}$, Juliana M.S.L. Alonso ${ }^{2}$, Marinaldo Guilhermino ${ }^{3}$, Adriana A. H. Brandão ${ }^{4}$, Ana Sueli \\ R. Cavalcante ${ }^{5}$
}

\author{
${ }^{1}$ PhD student in Oral Biopathology, UNESP - Universidade Estadual Paulista, São José dos Campos Dental School, São José dos \\ Campos, São Paulo, Brazil \\ ${ }^{2} \mathrm{PhD}$ in Oral Biopathology, UNESP - Universidade Estadual Paulista, São José dos Campos Dental School, São José dos Cam- \\ pos, São Paulo, Brazil \\ ${ }^{3}$ Dentist Graduated, UNESP - Universidade Estadual Paulista, São José dos Campos Dental School, São José dos Campos, São \\ Paulo, Brazil \\ ${ }^{4} \mathrm{PhD}$, Assistant Professor, Department of Bioscience and Oral Diagnosis, UNESP - Universidade Estadual Paulista, São José dos \\ Campos Dental School, São José dos Campos, São Paulo, Brazil \\ ${ }^{5} \mathrm{PhD}$, Associate Professor, Department of Bioscience and Oral Diagnosis, UNESP - Universidade Estadual Paulista, São José \\ dos Campos Dental School, São José dos Campos, São Paulo, Brazil.
}

Correspondence:

Márcia Hatakeyama.

Engenheiro Francisco José Longo, 777.

São José dos Campos - SP - Brasil.

Postcode: 12245-000.

E-mail:marciah23@hotmail.com

Received: 05/12/2009 Accepted: $25 / 01 / 2010$
Hatakeyama M, Alonso J, Guilhermino M, Brandão A, Cavalcante A. Verruciform xanthoma located in anterior gingiva. J Clin Exp Dent. 2010;2(2):e82-4.

http://www.medicinaoral.com/odo/volumenes/v2i2/jcedv2i2p82.pdf

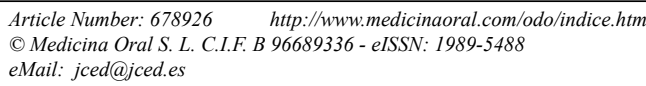

\begin{abstract}
Verruciform xanthoma (VX) is a relatively rare benign lesion and oral predominantly, which occasionally affects skin and genital mucosa. It appears as a papule or single plaque showing a verrucous or papillomatous aspect, with variable color from reddish pink to gray. In majority of oral cases, it affects gingiva and alveolar mucosa such a solitary lesion. Histopathological findings are foamy histiocytes within elongated dermal papillae. Treatment consists of conservative excision surgery and recurrence is rare. A clinical case is reported, located in anterior gingiva, showing good prognosis, without recurrence. There was no concomitant oral lesion associated. Local trauma was the only possibility suggested to be related to etiology. No relevant alterations in laboratory exams (hemogram, total cholesterol, HDL, LDL, VLDL, glycose and glycolized hemoglobin) were found. The origin of the lesion remains unclear and investigation for possible associations with other lesions that could present greater risk of carcinogenesis is required.
\end{abstract}

Key words: Xanthomatosis, mouth, foam cells. 


\section{Introduction}

Verruciform xanthoma (VX) is a rare benign lesion and oral predominantly that can also affect skin and genital mucosa (1). First described by Shafer in 1971 (2), it is characterized by histiocytes with lipid accumulation in the subepithelial papillary area (3). The etiology and pathogenesis of this lesion remain unclear. The aim of this article is to describe a rare case diagnosed as VX based on clinical and histopathological examination, and make a brief review of the literature.

\section{Case report}

Patient white, male, aged 38 years-old, underwent dental treatment due to the presence of a verrucous plaque (Fig.1) of approximately $10 \mathrm{~mm} \times 6 \mathrm{~mm}$, located in anterior gingiva, which presented as asymptomatic, with slow, gradual growth evolving over 4 years.

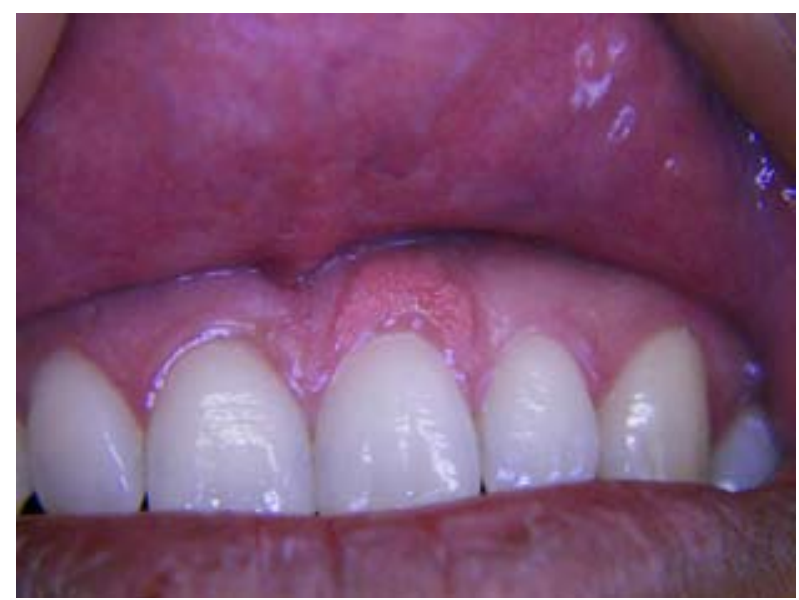

Fig. 1. Verrucous plaque in anterior gingival

The occurrence of gingival trauma while brushing his teeth at the time of lesion onset was cited and gingival recession was observed in several areas. No relevant alterations in laboratory exams were found (hemogram, total cholesterol, HDL, LDL, VLDL, glycose and glycolized hemoglobin). Excisional biopsy was performed to obtain material for further examination. Histopathological examination revealed stratified squamous epithelium, parakeratosis, hyperplasia with uniform crest length (Fig. 2), hydropic degeneration and some areas of basal layer duplication and exocytosis. In the lamina propria, chronic inflammatory infiltration was observed and in subepithelial and papillary areas, numerous macrophages presented foam cytoplasm and granules in their interior (Fig. 3). Periodic follow-up of the patient has been ongoing since August, 2007, without recurrence.

\section{Discussion}

According to the etiology, given the occurrence of VX in masticatory mucosa, mainly in the gingiva, the possibility of trauma or inflammatory etiology can be con-

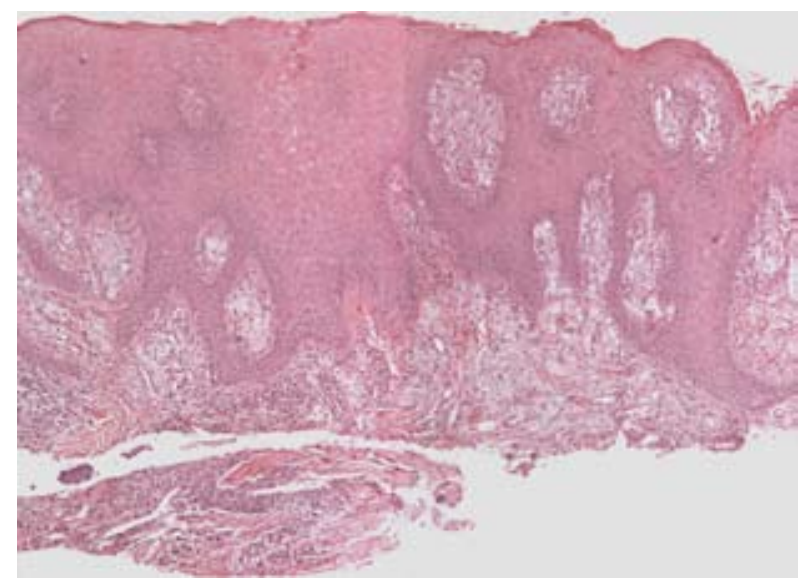

Fig. 2. Epithelial hyperplasia with uniform crest length (Hematoxylin and Eosin-original magnification 25X)

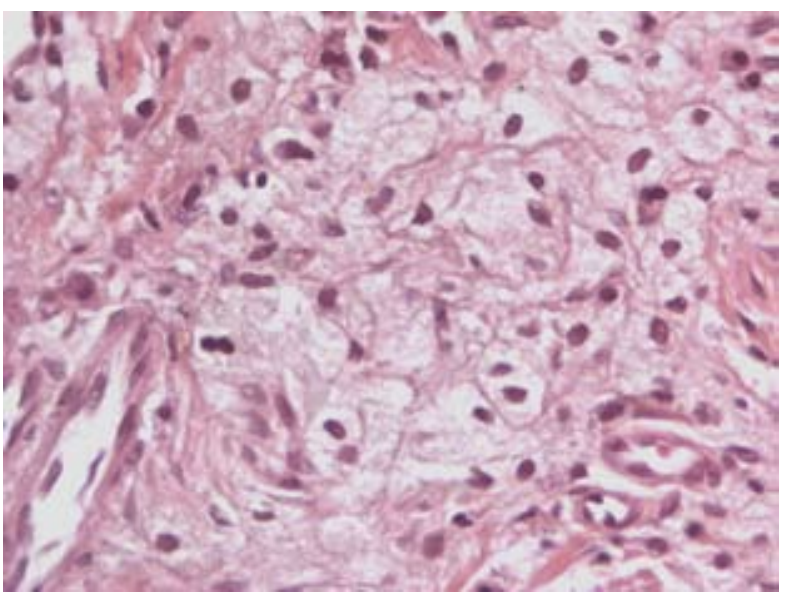

Fig. 3. Numerous foam histiocytes located in the subepithelial papillary area (Hematoxylin and Eosin - original magnification 400X)

sidered (4). Ide et al. (5) suggested some possible oral agents as wet microenvironment, periodontal pathogens, mechanical stimuli, tobacco, alcohol, drugs, sensitizing or allergic substances of foodstuffs and dental materials. In addition, VX associated with other lesions caused by epithelial damage have occurred, including epidermolysis bullosa (6), pemphigus vulgaris, graft versus host disease (1), lichen planus $(1,7)$, lupus erythematosus and epithelial dysplasia (1). Viral infection could be associated to the lesion, however $\mathrm{Hu}$ et al. (8) did not detect human papillomavirus in their cases by in situ hybridization. Immune response was also related to VX pathogenesis (9). The same last authors suggested that the foam cells originate from a monocyte/macrophage lineage. In respect to the accumulation of lipid inside foam cells, it is still not clear (8).

VX presents as a papule or single plaque showing a verrucous or papillomatous aspect, with variable color from reddish pink to gray, it is asymptomatic, has a low growth rate and evolves to sizes varying from 0.2 to $2 \mathrm{~cm}$ (3). In majority of cases, it affects gingiva and alveolar mucosa such a solitary lesion (10), however a rare disse- 
minated VX was described involving multifocal lesions on the skin and in oral and genital mucosa (11). Clinically, differential diagnosis should include papilloma and verruga vulgar. Misdiagnosis with verrucous carcinoma and squamous cell carcinoma (SCC) was also done on clinical and histologic diagnosis $(7,10)$.

Treatment consists of conservative excisional surgery and recurrence is rare (1). In the literature, no conclusive evidence of the malignant transformation of preexisting VX exists (4); although, there are some reports of no oral VX associated with SCC $(12,13)$. Murat-Susić et al. (6) presented a case of VX associated with epidermolysis bullosa and highlighted that the concomitant presence of VX in patients with epidermolysis bullosa could pose an increased risk of SCC occurrence. Drummond et al. (10) reported one case of VX associated with carcinoma in situ and high epithelium dysplasia adjacent to SCC, located in the buccal floor. Thus, they advised that VX biopsies should be performed with stricter criteria and surgical margins that include adjacent tissues, so that histological investigation could assure that no other lesion was involved.

A case of $\mathrm{VX}$ in anterior gingiva, is reported with easy diagnosis by routine histopathological exams. A brief review of the literature revealed that the lesion has unknown origin and suggested the need to investigate associations with other epithelium lesions, especially those related to greater carcinogenesis risk.

\section{References}

1. Damm DD, Fantasia JE. Rough white patch of gingiva. Verruciform xanthoma. Gen Dent. 2002; 50:378-80.

2. Shafer WG. Verruciform xanthoma. Oral Surg Oral Med Oral Pathol.1971; 31:784-49.

3. Nowparast B, Howell FV, Rick GM. Verruciform xanthoma. A clinicopathologic review and report of fifty-four cases. Oral Surg Oral Med Oral Pathol. 1981; 51:619-25.

4. Rawal SY, Kalmar JR, Tatakis DN. Verruciform xanthoma: imunohistochemical characterization of xanthoma cell phenotypes. J Periodontol. 2007; 78: 504-9.

5. Ide F, Obara K, Yamada H, Mishima K, Saito I, Kusama K. Cellular basis of verruciform xanthoma: immunohistochemical and ultrastructural characterization. Oral Dis. 2008; 14:150-7.

6. Murat-Susić S, Pastar Z, Dobrić I, Camino Varela A, Hutinec Z, Husar K, et al. Verruciform xanthoma in recessive dystrophic epidermolysis bullosa Hallopeau-Siemens. Int J Dermatol. 2007;46:955-9.

7. Polonowita AD, Firth NA, Rich AM. Verruciform xanthoma and concomitant lichen planus of the oral mucosa. Int J Oral Maxillofac Surg. 1999; 28:62-6.

8. Hu JA, Li Y, Li S. Verruciform xanthoma of the oral cavity: clinicopathological study relating to pathogenesis. Report of three cases. APMIS. 2005; 113:629-34.

9. Shin HI, Choi KS, Nagatsuka H, Murata M, Nagai N. Verruciform xanthoma of the oral mucosa: an immunohistochemical and ultrastructural study of two cases. Oral Oncol. 1997; 33:279-83.

10. Drummond JF, White DK, Damm DD, Cramer JR. Verruciform xanthoma within carcinoma in situ. J Oral Maxillofac Surg. 1989; 47:398-400.

11. Sopena J, Gamo R, Iglesias L, Rodriguez-Peralto JL. Disseminated verruciform xanthoma. Br J Dermatol. 2004; 151:707-30.

12. Takiwaki H, Yokota M, Ahsan K, Yokota K, Kurokawa Y, Ogawa I. Squamous cell carcinoma associated with verruciform xanthoma of the penis. Am J Dermatopathol .1996; 18:551-4.

13. Mannes KD, Dekle CL, Requena L, Sangueza OP. Verruciform xanthoma associated with squamous cell carcinoma. Am J Dermatopathol. 1999; 21:66-9. 